\title{
A STUDY ON THE VOCABULARY LEARNING STRAGIES OF HIGH SCHOOL STUDENTS IN JIANGSU PROVINCE
}

\author{
Changying Huang \\ College of Foreign Language, Yangzhou University, China \\ DOI: 10.46609/IJSSER.2021.v06i04.002 URL: https://doi.org/10.46609/IJSSER.2021.v06i04.002
}

\begin{abstract}
Based on the current pressure of college entrance examination reform in Jiangsu Province, it is particularly necessary for high school students to master multiple forms of English learning strategies. According to learning strategy theory of O' Malley and Chamot, this paper conducts a questionnaire survey of 93 students to explore the overall situation of high school students' vocabulary learning strategies. The results show that: (1)High school students are proficient at using multiple strategies to learn vocabulary; (2) There exist differences in the use of vocabulary learning strategies between students of Grade ten and Grade twelve; (3) There is a correlation between vocabulary learning strategies and gender.
\end{abstract}

Keywords: High school students; Vocabulary learning; Learning strategies

\section{Introduction}

In April 2019, Jiangsu Province officially released the College Entrance Examination reform plan, which is applicable to Grade ten students enrolled in the fall of 2018, i.e., 2021 high school graduates. The new plan adopts the "3+1+2" model-the form of "3 subjects (Chinese, Mathematics and English) +1 (Physics or History) +2 subjects (Chemistry or Biology or Politics or Geography)"; the total score of English has changed from 120 to 150, and the total score of the College Entrance Examination has increased from 480 to 750 . It is not difficult to see that on the one hand, the new scheme also brings students' learning pressure invisibly on the basis of satisfying students' subject preferences; on the other hand, for most students with poor foundations, improving English scores is "adding insult to injury". Then, standing at the crossroads of College Entrance Examination reform, it is the correct path for high school students in the province that they should master and apply appropriate vocabulary learning strategies in order to get out of the "English predicament".

Vocabulary is the prerequisite for learning English language. Wilkins (1978) pointed out that "Without grammar, there are few things that can be expressed; but without vocabulary, nothing 


\section{International Journal of Social Science and Economic Research}

ISSN: $2455-8834$

Volume:06, Issue:04 "April 2021"

can be expressed." It can be seen that vocabulary plays a big role in language learning. In high school English learning, teachers and students attach great importance to vocabulary learning, but most of them focus on the form of memorizing vocabulary lists and filling in the blanks, whose effect is not satisfactory. As a matter of fact, Chinese students generally lack effective vocabulary learning strategies (Chen Hui, 2001), but various strategies obviously contribute to improving their vocabulary learning level. In recent years, there have been lots of research results on English vocabulary learning strategies. As far as foreign scholars are concerned, Oxford (1990) divided learning strategies into direct and indirect categories on the basis of predecessors; Cohen (1990) and Nation (1990) also classified specific vocabulary learning strategies; Knight (1994) conducted a survey of 112 sophomore students on vocabulary comprehension in reading; Luppescu and Day (1993) took 293 English college students as the survey object, and proved the role of dictionary in vocabulary learning; It is believed that when students are eager to acquire vocabulary, they can learn vocabulary well in class(Allen,2002). In reference to domestic scholars, the case analysis of Wen Qiufang (1995: 61-66) shows that the difference between successful and unsuccessful English learning lies in learning strategies; Wu Xia and Wang Qiang (1998) researched on the learning strategies of non-English majors, emphasizing Chinese students are adept at applying multiple vocabulary learning strategies; Liu Jinkai (1999:3-5) explored the performance of good and poor students in vocabulary guessing, and concluded that there are differences between the two types of students; a comparative study of 106 English college undergraduates on vocabulary learning strategies (Feng Yufang ,2003), proved that there are differences in the use of strategies among high and low grades. However, the author find that there is very little research literature on the use of vocabulary learning strategies in elementary and middle schools. As Li Meng (2018) said, "The research objects of relevant papers in the past five years are mostly students with a college degree or above. Very little research has been done for vocabulary learning strategies of primary and middle school students ."

Therefore, based on the research of academic predecessors, the author tries to analyze the similarities and differences in the use of vocabulary learning strategies by students of different grades in high school, and explore the relationship between gender and learning strategies. This article adopts statistical methods to analyze the data of the questionnaire survey, whose conclusions will have certain benefits for teachers and students in high schools in Jiangsu Province in English vocabulary learning.

\section{Method of research}

\subsection{Object of research}


International Journal of Social Science and Economic Research

ISSN: 2455-8834

Volume:06, Issue:04 "April 2021"

The subjects of this study are 93 students from Guanyun Senior Middle School in Jiangsu Province. Among them, there are 49 Grade ten students (male:female=28:21) and 44 Grade twelve students( called 2021 high school graduates, male:female=19:25). These students have received seven to nine years of English teaching. They are selected as the survey subjects, mainly for the following two reasons: First, the English level of high school freshmen is equivalent to that of junior middle school students, and they have not yet received special training in high school; Grade twelve students have been exposed to learning and training for two years, and therefore their English proficiency has more or less enhanced. Second, it can analyze English proficiency between the two grades of students in order to explore their differences in vocabulary learning strategies, and then provide feasible teaching suggestions for middle school teachers.

\subsection{Questionnaire}

The questionnaire mainly uses Likert's five-level scale (1=strongly disagree, $5=$ strongly agree), and the theory of question design is mainly derived from the learning strategy method of O'Malley and Chamot (1990). According to this learning strategy, the questions of questionnaire are roughly divided into three parts, namely concepts, meta-cognitive strategies and cognitive strategies. Among them, there are three concepts: (1)memorizing by rote is an important way to learn vocabulary; (2) vocabulary should be learned in use; (3) vocabulary should be learned in context. There are four types of meta-cognitive strategies, including planning, self-supervision, self-evaluation and selective attention. There are eight kinds of cognitive strategies, including memorizing by rote, context, dictionary look-up, guessing, association, problem solving, reading and classification.

A total of 93 questionnaires were issued this time, all of which were recovered, 89 valid questionnaires. The overall reliability coefficient (Alpha $=0.736>0.7$ ) and validity coefficient $(\mathrm{KMO}=0.601>0.5)$ of the questionnaire are both high, indicating that the reliability of the questionnaire is strong (see Table 1 and Table 2). In order to study the questionnaire in a deeper aspect, this paper uses SPSS16.0 software to analyze the data.

Table 1. Analysis of the reliability coefficient of the questionnaire

\begin{tabular}{c|c|c}
\hline \multicolumn{3}{c}{ Reliability Statistics } \\
\hline Cronbach's Alpha & Cronbach's Alpha Based on Standardized Items & N of Items \\
\hline .736 & .741 & 15 \\
\hline
\end{tabular}

Note: When $\mathrm{KMO}>0.5$, the validity is reliable. 
International Journal of Social Science and Economic Research

ISSN: 2455-8834

Volume:06, Issue:04 "April 2021"

Table 2. Analysis of the validity coefficient of the questionnaire

\begin{tabular}{|c|c|c|c|c|c|}
\hline Category & Variable & Validity & Category & Variable & Validity \\
\hline \multirow{3}{*}{ View } & E1 & .552 & \multirow{8}{*}{$\begin{array}{l}\text { Cognitive } \\
\text { strategies }\end{array}$} & $\mathrm{E}$ & .655 \\
\hline & $\mathrm{M}$ & .729 & & $\mathrm{~F}$ & .630 \\
\hline & F1 & .742 & & G & .726 \\
\hline \multirow{5}{*}{$\begin{array}{c}\text { Meta- } \\
\text { cognitive } \\
\text { strategies }\end{array}$} & $\mathrm{A}$ & .551 & & $\mathrm{H}$ & .593 \\
\hline & B & .780 & & I & .690 \\
\hline & $\mathrm{C}$ & .738 & & $\mathrm{~J}$ & .738 \\
\hline & \multirow{2}{*}{ D } & \multirow{2}{*}{.772} & & $\mathrm{~K}$ & .752 \\
\hline & & & & $\mathrm{L}$ & .735 \\
\hline
\end{tabular}

Note: When KMO $>0.5$, the validity is reliable.

A: Make plans; B: Self-supervision; C: Self-evaluation; D: Selective attention;

E: Memorizing by rote; F: Context;G: Dictionary look-up; H: Guessing; I: Association;

J: Doing exercise; K: Reading;L: Classification; M:Application; E1:Memorizing by rote; F1:Context

\section{Results and discussion}

\subsection{The use of vocabulary learning strategies by high school students}

This questionnaire adopts Likert's five-level scale. Therefore, if the average values of learning strategies are greater than 3, it means that they are used frequently by students; otherwise, it is not used frequently enough. The results of data analysis are as follows:

Table 3. Descriptive results of vocabulary learning strategies of high school students $(\mathbf{N}=\mathbf{8 9})$

\begin{tabular}{|c|c|c|c|c|c|c|c|}
\hline Category & Variable & Mean & $\begin{array}{c}\text { Standard } \\
\text { Deviation }\end{array}$ & Category & Variable & Mean & $\begin{array}{l}\text { Standard } \\
\text { Deviation }\end{array}$ \\
\hline \multirow[t]{3}{*}{ View } & E1 & 2.76 & 1.087 & \multirow{8}{*}{$\begin{array}{l}\text { Cognitive } \\
\text { strategies }\end{array}$} & E & 3.64 & 1.121 \\
\hline & $\mathrm{M}$ & 4.15 & .762 & & $\mathrm{~F}$ & 3.80 & 1.057 \\
\hline & F1 & 4.36 & .589 & & $\mathrm{G}$ & 3.10 & 1.398 \\
\hline \multirow{5}{*}{$\begin{array}{c}\text { Meta- } \\
\text { cognitive } \\
\text { strategies }\end{array}$} & A & 3.52 & 1.024 & & $\mathrm{H}$ & 3.91 & .887 \\
\hline & $\mathrm{B}$ & 3.60 & 974 & & I & 3.78 & .986 \\
\hline & $\mathrm{C}$ & 3.65 & 1.012 & & $\mathrm{~J}$ & 3.21 & 1.133 \\
\hline & D & 308 & 1044 & & $\mathrm{~K}$ & 3.36 & 1.151 \\
\hline & & 3.98 & 1.044 & & $\mathrm{~L}$ & 3.56 & 1.206 \\
\hline
\end{tabular}

A: Make plans; B: Self-supervision; C: Self-evaluation; D: Selective attention;

E: Memorizing by rote; F: Context;G: Dictionary look-up; H: Guessing; I: Association;

J: Doing exercise; K: Reading;L: Classification; M:Application; E1:Memorizing by rote; F1:Context

It can be seen from Table 3 that among the three concepts, except the average value of the "memorizing by rote" strategy less than 3, the average values of the other two strategies are over 3. The order of the average values is: context $(M=4.36)>$ application $(M=4.15)>$ memorizing by 


\section{International Journal of Social Science and Economic Research}

ISSN: $2455-8834$

Volume:06, Issue:04 "April 2021"

rote $(M=2.76)$. This shows that compared with "memorizing by rote", students will use the latter two strategies more frequently (i.e., memorizing vocabulary through context and understanding vocabulary in use), and believe that the latter two strategies are more effective in vocabulary learning. This result is consistent with that of Wang Qiang (1998).

The average values of the four meta-cognitive strategies are between 3.52-3.98, which indicates that these strategies are favored by students. Among them, "selective attention" scored the highest, while the result of "planning" was the opposite. This result is slightly different from the study of Feng Yufang (2003). Meta-cognitive strategy is a typical procedural learning strategy, through which students can effectively monitor their own cognitive process and results.

The average values of all cognitive strategies are greater than 3 , indicating that these strategies are generally accepted by students. The order of their average values is: guessing $(\mathrm{M}=3.91)>\operatorname{context}(\mathrm{M}=3.80)>$ association $(\mathrm{M}=3.78)>$ memorizing rote $(\mathrm{M}=3.64)>$ classification $(\mathrm{M}=3.56)>\operatorname{reading}(\mathrm{M}=3.36)>$ problem solving $(\mathrm{M}=3.21)>$ dictionary lookup(M=3.10) According to the results, the acceptance of "guessing" strategy and "context" strategy is higher, while that of "problem solving" strategy and "dictionary look-up" strategy is lower. Considering the high school students' pressing pace of study and life, and it is not difficult to find the relationship between these strategies: based on the pressure of "excessive assignments tactic", students hate doing exercise, and are reluctant to spend more time looking up the dictionary when encountering new words. Instead, they tend to adopt " shortcuts", such as "guessing" and other strategies. In fact, for students with a certain vocabulary reserve, "guessing" and "context" are indeed effective strategies.

From the above analysis, the author find an invisible problem, which is similar to the study of Wang Qiang (1998). On the one hand, students disagree that "memorizing by rote" $(\mathrm{M}=2.76)$ is an important strategy for vocabulary learning; on the other hand, in cognitive strategies, they perform frequent use of "memorizing by rote" $(M=3.64)$. This phenomenon shows that while students deny the idea of memorizing by rote, they cannot get rid of the use of this strategy. Therefore, it is particularly necessary to cultivate the habit of forming and applying multiple learning strategies.

\subsection{The Differences in Vocabulary Learning Strategies between the two grades}

The author conducted an independent sample T-test on vocabulary learning strategies for Grade ten students (48) and Grade twelve students (41), in order to explore the differences in vocabulary learning strategies between the two grades. The result is as follows: 
International Journal of Social Science and Economic Research

ISSN: 2455-8834

Volume:06, Issue:04 "April 2021"

Table 4. T-test of vocabulary learning strategies of students of senior one and three $(\mathrm{N}=89)$

\begin{tabular}{|c|c|c|c|c|c|c|c|}
\hline \multirow[b]{2}{*}{ Category } & \multirow[b]{2}{*}{ Variable } & \multicolumn{2}{|c|}{ Grade ten Students } & \multicolumn{2}{|c|}{ Grade twelve Students } & \multirow[b]{2}{*}{$\mathrm{T}$} & \multirow[b]{2}{*}{$\mathrm{P}$} \\
\hline & & Mean & $\begin{array}{c}\text { Standard } \\
\text { Deviation }\end{array}$ & Mean & $\begin{array}{c}\text { Standard } \\
\text { Deviation }\end{array}$ & & \\
\hline \multirow{3}{*}{ View } & E1 & 2.79 & 1.071 & 2.73 & 1.119 & .258 & .797 \\
\hline & M & 3.96 & .771 & 4.37 & .698 & -2.595 & .011 \\
\hline & $\mathrm{F} 1$ & 4.33 & .559 & 4.39 & .628 & -.453 & .652 \\
\hline \multirow{4}{*}{$\begin{array}{c}\text { Meta- } \\
\text { cognitive } \\
\text { strategies }\end{array}$} & $\mathrm{A}$ & 3.12 & 1.024 & 3.98 & .821 & -4.348 & .000 \\
\hline & B & 3.42 & .871 & 3.80 & 1.054 & -1.902 & .060 \\
\hline & $\mathrm{C}$ & 3.56 & .897 & 3.76 & 1.135 & -.898 & .372 \\
\hline & $\mathrm{D}$ & 4.00 & 1.111 & 3.95 & .973 & .218 & .828 \\
\hline \multirow{8}{*}{$\begin{array}{l}\text { Cognitive } \\
\text { strategies }\end{array}$} & A & 3.83 & 1.018 & 3.41 & 1.204 & 1.779 & .079 \\
\hline & B & 3.60 & 1.144 & 4.02 & .908 & -1.931 & .057 \\
\hline & C & 3.08 & 1.350 & 3.12 & 1.470 & -.129 & .898 \\
\hline & $\mathrm{D}$ & 3.71 & .849 & 4.15 & .882 & -2.382 & .019 \\
\hline & $\mathrm{I}$ & 3.44 & .823 & 4.17 & 1.022 & -3.748 & .000 \\
\hline & $\mathrm{J}$ & 3.10 & 1.189 & 3.34 & 1.063 & -.985 & .327 \\
\hline & K & 2.85 & 1.091 & 3.95 & .921 & -5.075 & .000 \\
\hline & L & 2.96 & 1.148 & 4.27 & .837 & -6.058 & .000 \\
\hline
\end{tabular}

A: Planning; B: Self-supervision; C: Self-evaluation; D: Selective attention;

E: Memorizing by rote; F: Context; G: Dictionary look-up; H: Guessing; I: Association;

J: Doing exercise; K: Reading; L: Classification; M:Application; E1:Memorizing by rote; F1:Context

As is the test result shown, there are varying degrees of differences in concepts, cognitive strategies, and meta-cognitive strategies between Grade ten and Grade twelve students. Among them, in the use of most vocabulary learning strategies, the performance of Grade twelve students is better than that of Grade ten students, i.e., Grade twelve students will use these strategies more frequently. It can be seen from Table 4 that some strategies have significant differences $(\mathrm{P}<0.05)$. The specific analysis is as follows:

At the conceptual level, the "application" strategy ( $\mathrm{T}=-2.595, \mathrm{P}=.011)$ showed significant differences, which means that compared with Grade ten students, Grade twelve students are more inclined to learn vocabulary in use. There is little difference between the "memorizing by rote" and "context" strategies of the two graders. They both think that the context can improve the efficiency of vocabulary learning, and it is not wise to learn vocabulary by memorizing by rote alone.

At the level of meta-cognitive strategies, the two groups of students differed in the "planning" strategy ( $\mathrm{T}=-4.348, \mathrm{P}=.000)$, but not in other strategies. However, the author find that in addition to "selective attention", the two strategies, namely "self-supervision" and "self-evaluation", both present the characteristics of "Grade twelve > Grade ten" on the average. It shows that in general, 


\section{International Journal of Social Science and Economic Research}

ISSN: $2455-8834$

Volume:06, Issue:04 "April 2021"

Grade twelve students are adept at using meta-cognitive strategies. In other words, they are better at controlling their own strategies during learning vocabulary to achieve the purpose of efficiency; while the situation of Grade ten students is the opposite.

At the level of cognitive strategies, the two groups of students mainly took on significant differences in four strategies, namely "guessing" ( $\mathrm{T}=-2.382, \mathrm{P}=.019)$ and "association" ( $\mathrm{T}=-$ 3.748, $\mathrm{P}=.000)$, "reading" ( $\mathrm{T}=-5.075, \mathrm{P}=.000)$ and "classification" $(\mathrm{T}=-6.058, \mathrm{P}=.000)$. On the one hand, after more than two years of high school English learning, Grade twelve students have mastered a certain amount of vocabulary, which makes it easier to highlight advantages in using strategies such as "guessing" and "association"; while Grade ten students have just entered high school, whose English level is equivalent to that of secondary school students. Therefore, it is relatively difficult for Grade ten students to use the strategies of "guessing", "associating", "reading" and "classification". On the other hand, although there is no difference between the two groups of students in the "memorizing by rote" and "context" strategies, the average values of the two strategies are quite different. It can be seen that Grade ten students are more inclined to mechanized vocabulary learning; in addition, regardless of judging from the T test result or the average value, the two groups of students did not frequently use the "dictionary look-up" strategy. This may be mainly due to two reasons: the one is that the heavy learning burden makes students have no time to look up dictionaries, and the other is that the importance of dictionaries are not emphasized in class, resulting in students not fostering the habit of looking up dictionaries or not possessing the ability.

From the data in Table 4 and the above analysis, there is no significant difference in the "context" strategy, which is inconsistent with the research results of Feng Yufang (2003) and Wang Qiang (1998). Feng Yufang (2003) pointed out that "A high level of language skills is necessary to guess vocabulary from context." Although the study indicates that "context" strategies are popular among students, the results are not significant. It also proves that the overall language proficiency of high school students is low. At the same time, it is worth mentioning that the strategies favored by high school students (such as guessing, reading, etc.) are often only reflected in the case of reading comprehension in English, because in the circle of test-oriented education, there is no space and time for most students to improve their language proficiency.

\subsection{Comparison of the relationship between gender and learning strategies}

In order to explore the relationship between gender and learning strategy, this article uses gender as an independent variable and learning strategy as a dependent variable to get the correlation coefficient between the two. The results are shown in Table 5: 
International Journal of Social Science and Economic Research

ISSN: 2455-8834

Volume:06, Issue:04 "April 2021"

Table 5. The correlation coefficient between gender and vocabulary learning strategies( $R$ )

\begin{tabular}{|c|c|c|c|c|c|c|c|c|}
\hline & \multicolumn{3}{|c|}{ View } & \multicolumn{5}{|c|}{ Meta-cognitive strategies } \\
\hline & E1 & $\mathrm{M}$ & F1 & A & B & $\mathrm{C}$ & $\mathrm{D}$ & \\
\hline $\mathrm{R}$ & -.003 & $.246^{*}$ & $.210^{*}$ & .137 & .014 & -.044 & $.261 *$ & \\
\hline $\mathrm{P}$ & .977 & .020 & .049 & .199 & .896 & .681 & .014 & \\
\hline \multicolumn{9}{|c|}{ Cognitive strategies } \\
\hline & $\mathrm{E}$ & $\mathrm{F}$ & $\mathrm{G}$ & $\mathrm{H}$ & I & $\mathrm{J}$ & $\mathrm{K}$ & $\mathrm{L}$ \\
\hline $\mathrm{R}$ & $.253^{*}$ & $.285 * *$ & $.264 *$ & .131 & $.352 * *$ & $.223 *$ & .147 & .059 \\
\hline $\mathrm{P}$ & .017 & .007 & .012 & .222 & .001 & .036 & .170 & .581 \\
\hline
\end{tabular}

As Table 5 can be seen, the "application" and "context" strategies in the concept exist a positive correlation with gender; among the meta-cognitive strategies, "selective attention" strategy has a strong correlation with gender. Different genders influence the frequency of using this strategy; among the cognitive strategies, in addition to "guessing", "reading" and "classification" strategies, the other five strategies are positively correlated with gender, among which "association" strategy $(\mathrm{R}=.352 * *, \mathrm{P}=.001)$ has the strongest correlation with gender; at the same time, the "memorizing by rote" in the concept and the "self-assessment" in the meta-cognitive strategies are negatively related to gender. This shows that when guiding students to choose vocabulary learning strategies, middle school teachers should take full consideration to gender differences, so as to help them achieve the right learning strategies.

\section{Conclusion and suggestions}

Through this survey, the following main conclusions can be drawn: (1) High school students tend to apply a variety of strategies to learn vocabulary, among which strategies such as "planning", "guessing", and "associating" are particularly favored by students; "memorizing by rote" and "dictionary look-up" strategies are not popular among students. (2) There are differences in the use of vocabulary learning strategies between Grade ten and Grade twelve students. Compared with Grade ten students, Grade twelve students are more inclined to using cognitive strategies, such as "guessing", "associating", and "reading"; in terms of meta-cognitive strategies, "planning" is popular among Grade twelve students. In general, with the improvement of language proficiency, students apply vocabulary learning strategies more and more flexibly. (3) There is a correlation between vocabulary learning strategies and gender. Among them, "association", "context", "dictionary look-up" and other strategies exist a strong correlation with gender.

For high school teachers and students, especially teachers and students in Jiangsu Province, this 


\section{International Journal of Social Science and Economic Research}

ISSN: $2455-8834$

Volume:06, Issue:04 "April 2021"

research has instructive significance. First of all, class teaching should pay more attention to consciously advocate and teach various forms of vocabulary learning strategies, and to encourage students to cultivate good habits of using these strategies at the beginning. Over time, students will be able to internalize the habit into a kind of learning ability, and truly become the master of study, so as to get rid of the "vocabulary learning predicament" as soon as possible. Secondly, teachers should teach students in accordance with their aptitude according to the characteristics of students of different grades. Teachers have better encourage lower-grade students to develop new learning strategies based on mechanized vocabulary learning; guide upper-grade students to strengthen the mastery of meta-cognitive strategies based on the use of cognitive strategies, so that they can learn to regulate themselves in the process of learning vocabulary. Thirdly, teachers ought to tell students the correlation between gender and learning strategies. Meanwhile students should choose appropriate learning strategies according to their own characteristics to achieve the purpose of improving their English language proficiency.

\section{References}

[1] Wilkins, D. A. Linguistics in Language Teaching [M]. London: Edward Arnold, 1978.

[2] Oxford, R.L. Language learning strategies: What every teacher should know [M]. New York: Newbury House, 1990.

[3] Cohen, A. D. Language Learning [M]. New York: Newbury House, 1990.

[4] Nation, I. S. P. Teaching and Learning Vocabulary [M]. New York: Newbury House, 1990.

[5] O’Malley, J. \& A. Chamot (eds). Learning Strategies in Second Language Acquisition [M]. Cambridge: CUP, 1990.

[6] Knight,S.Dictionary Use While Reading: The Effects on Comprehension and Vocabulary Acquisition for Students of Different Verbal Abilities[J]. The Modern Language Journal 1994, 78(3):285-299.

[7] Luppescu,S.\&Day,R.Reading,Dictionaries and Vocabulary Learning[J]. Language Learning Journal.1993(2):263-279.

[8] Allen,V.F.Techniques in Teaching Vocabulary[M].Shanghai:Shanghai Foreign Language Education Press,2002.

[9] Wen Qiufang. Differences in learning methods between successful and unsuccessful English speakers[J] .Foreign Language Teaching and Research, 1995,(3). 
[10] Wu Xia, Wang Qiang. Vocabulary Learning Strategies for Non-English Major Undergraduates[J]. Foreign Language Teaching and Research, 1998, (1): 53-57.

[11] Liu Jinkai. Research on Foreign Language Learning Strategies_-Word Guessing Ability and Foreign Language Proficiency[J]. Foreign Language Teaching, 1999(03):3-5.

[12] Chen Hui. Strategies for non-English major Chinese students to learn English vocabulary-A survey report analyzing vocabulary learning strategies[J]. Foreign Language Teaching, 2001(06):46-51.

[13] Feng Yufang. A Comparative Study on the Vocabulary Learning Strategies of English Majors[J]. Foreign Language Circles, 2003(02):66-72.

[14] Li Meng. A Summary of Domestic Research on English Vocabulary Learning in the Past 5 Years[J]. Overseas English, 2018(23):217-219.

[15] Qian Ting. Study on the effect of vocabulary strategy training on English reading of sixth grade students[D]. Suzhou University, 2018. 